\title{
Assessment of The Burden of, and Women's Experience With Screening For, Maternal Perinatal Depression in Kuwait
}

\author{
Rand Alenezi \\ Arabian Gulf University \\ Madhawi Alduosari \\ Arabian Gulf University \\ Aseel M. Alotaibi \\ Arabian Gulf University \\ Danah Alrasheedi \\ Arabian Gulf University \\ Lolwah Alenezi \\ Arabian Gulf University \\ Danah Naser \\ Arabian Gulf University \\ Albatool T. Alshammari \\ Arabian Gulf University \\ Sarah Alrasman \\ Arabian Gulf University \\ Lulwa J. Aldein \\ Arabian Gulf University \\ Amer J. Almarabheh \\ Arabian Gulf University \\ Jamil Ahmed ( $\sim$ jamilmga@agu.edu.bh ) \\ Arabian Gulf University
}

\section{Research Article}

Keywords: Assessment, screening, perinatal, COVID-19

Posted Date: November 2nd, 2021

DOI: https://doi.org/10.21203/rs.3.rs-1020117/v1 
License: (c) (i) This work is licensed under a Creative Commons Attribution 4.0 International License. Read Full License 


\section{Abstract \\ Background}

Perinatal depression can have a devastating impact upon the health and lives of the mothers and their children. Although guidelines are in place to properly screen women for perinatal depression in high income countries, there still is a possibility that some women may be missed. Identifying women with or at high risk of perinatal depression is even more important during COVID-19 pandemic. This study was aimed to measure prevalence and associated factors of perinatal depression, and to understand the women's experience of screening for perinatal depression in Kuwait.

\section{Methods}

Women who had recently attended antenatal and postnatal clinics in Kuwait during COVID-19 pandemic were approached through snowball sampling with the help of physicians in Kuwait in a cross-sectional online survey. They answered an online self-administered questionnaire consisting of Edinburgh postnatal depression scale, sociodemographic characteristics, and items about their experience of screening during antenatal and postnatal checkup. Out of the 158 women who answered this questionnaire, $75.3 \%$ were in their third trimester of pregnancy and the rest were in the postpartum period.

\section{Results}

Perinatal depression was possible in 31 (19.6\%) highly possible in 23 (14.6\%), and probable in 52 (32.9\%) women in our study, indicating an alarming prevalence of the condition in the sampled population. A large proportion of the sample (66.5\%) said that they were not aware of a screening process for perinatal depression, whereas only $5.7 \%$ said that they were screened for it. In the sample, $65.1 \%$ who were not screened for perinatal depression had perinatal depression $(P<0.05)$. The mean scores for variables representing family support and help were higher among the normal women than with perinatal depression $(P<0.001)$. Similarly, women with perinatal depression had scores towards disagreement when they were asked if they could easily talk about their problems and thoughts with their friends $(P<0.01)$.

\section{Conclusions}

Maternal perinatal depression was high in Kuwaiti women who were either in their third trimester or had just given birth to a baby. The lack of awareness about the screening process and extremely low levels of screening for perinatal depression indicates the need to improve these women's access to adequate screening services during and after pregnancy. 


\section{Background}

Perinatal depression is a mental health disorder in women around pregnancy and has a negative impact on mothers and their newborns (1). It is a type of depression that covers the period from 22 weeks of pregnancy until 7 days after birth (2). According to the American College of Obstetricians and Gynecologists one in every seven women is affected by minor or major depressive episodes during pregnancy (3). About $15 \%$ of women experience depression during their lifetime and most of them during perinatal period $(4,5)$; and about $11.9 \%$ of women have perinatal depression globally, with a range from $10-15 \%$ (6). Burden of perinatal depression in the middle east is also high. A study from Saudi Arabia and Oman showed that more than half of expecting mothers and almost a quarter respectively have perinatal depression (7). In Kuwait also, around $45 \%$ of the women suffer from postpartum depression (8).

Perinatal depression has been shown to be linked to several risk factors including exposure to intimate partner violence and abuse increasing the risk by five times (5). Women with traumatic events early in life, such as neglect or sexual abuse, or chronic diseases including maternal body mass index (9), pregnancy related anxiety and recent catastrophic events (10) are more likely to develop perinatal depression [11]. Life stress, lack of family and relative support, or social or financial support have also been linked to perinatal depression $(3,11)$. Poor socioeconomic status, stress, lack of a supportive partner and complications during pregnancy are other examples of other known and significant risk factors of perinatal depression (1). Low education level, with unplanned pregnancy, avoiding breastfeed, and a past history of depression may also cause perinatal depression (12). Some of the other risk factors are perceptions of problems related to taking care of the newborn, loss of the newborn baby and partner smoking. Whereas risk factors associated specifically with postnatal depression include depression during pregnancy, stressful events, traumatic birth experience, medical complications in the newborn or problems with breastfeeding, and a lack of social support $(3,13)$.

\section{Impact of perinatal depression}

Perinatal depression can have serious impact not only on the health of the pregnant mothers but also on their partners and newborn babies. Several studies on the negative consequences of perinatal depression conclude that if it is left untreated or not treated adequately, there can be irreparable damage to the fetus. Not only that, but also pregnant women who suffer from perinatal depression face high risk of premature delivery, low birth weight and delayed neurobehavioral development of the fetus $(3,13,14)$. Perinatal depression can have damaging effect on the wellbeing of the newborn, and that maternal emotional distress can even affect the fetus and impair the cognitive and behavioral development. Perinatal depression is attributed to inadequate prenatal care which can lead to poor nutritional health for the mothers and the infants, and a higher risk of infections in children $(13,15,16)$. In some cases, it can also lead to negative maternal-infant interaction, behavioral problems in children, and in severe cases suicide and infanticide have also been reported (17). Despite the seriousness of the impact of perinatal depression on the mothers, the baby and the other family members, perinatal depression remains 
underdiagnosed for one reason or the other (17). Perinatal depression may be unrecognized because many women may not reveal their feelings, and symptoms may not be obvious during brief consultations (17). Moreover, women also refrain from seeking treatment social or self-stigma, lack of awareness, fears regarding mental health treatment methods or unrealistic expectations of managing motherhood (18).

\section{Screening and treatment of peripartum depression}

It is necessary for physicians to understand these risk factors to identify women who are at a higher risk of developing perinatal depression because many women with perinatal depression may not seek necessary assistance that they need (19). Previous studies show that around $35.7 \%$ of women who are screened have perinatal depression (5). To determine perinatal depression in women, screening is necessary, and all women need to be screened during their antenatal and postnatal period. The American College of Obstetricians and Gynecologists suggests that screening for perinatal depression should be done at least once in every trimester by using standardized validated tools (3). Screening for perinatal depression is not currently a routine care everywhere but requires adequate attention to avoid missing potential women (13). Screening alone can have clinical benefit, and regular screening and monitoring behavioral changes and offering support through home visits is helpful to prevent perinatal depression $(20,21)$. Screening women during perinatal period could be more challenging during COVID-19 and it can have a debilitating impact on pregnant women's mental health, not only provoking new but also exacerbating existing mental health issues (22). A positive association between the number of women who experienced perinatal depression and the increased number of COVID-19 cases was found in Wuhan, China (23). The aim of this study was to assess the prevalence and associated factors of high-risk perinatal depression in women who had attended antenatal and postnatal clinics in Kuwait during COVID19 pandemic. A secondary objective was to determine if these women were screened for perinatal depression during their visits to antenatal or postnatal clinics, and to assess the effect of COVID-19 pandemic on high-risk perinatal depression.

\section{Methods}

\section{Study design}

A cross sectional online survey was conducted among women who had recently attended antenatal and postnatal clinics in Kuwait during COVID-19 pandemic. The online questionnaire allowed us to assess the prevalence of high-risk perinatal depression while maintaining the WHO recommended "physical distancing" during the COVID-19 pandemic.

\section{Study population and sample}

All the Kuwaiti women in their perinatal period attending antenatal or postnatal clinics were eligible to participate in the study. The perinatal period is defined as the period that commences at 22 completed weeks (154 days) of gestation and ends seven completed days after birth (2). We aimed to conveniently select at least 300 Kuwaiti women in this study. The sample size was determined based on the formula for a single population proportion where the assumptions included: prevalence of high-risk perinatal 
depression of $19 \%, 95 \%$ confidence level, and margin of error of $5 \%$. We expected a $25 \%$ non-response rate in our study and finally targeted to include 375 women by adding $25 \%$ to the actual estimated sample size.

\section{Inclusion and exclusion criteria}

The participants were included if they were: 1) Kuwaiti 2) able to read and write Arabic 3) agree to participate in the survey 4) had no known existing psychological problems. Women who were being treated from any medical conditions including trauma-related illnesses were also excluded from the study by assuming that the medical illness they were experiencing during the data collection might affect their mental status.

\section{Data collection}

The data were collected from the second week of January 2021 to the last week of May 2021. The study consisted of a standardized e-questionnaire which was generated using the Google Form, the survey was posted online via social media platforms (Twitter, Facebook, Instagram, and WhatsApp) publicly to facilitate snowball sampling and shared to the women by a resident in obstetrics and gynecology. The participants were also initially sought through a pediatrician, a gynecologist and obstetrician, a dermatologist, and a family physician who used their social media platforms to invite potential participants in the study. The women were asked to provide their email address or mobile number and those who agreed to participate in the study received an email with a link to the Google form-based questionnaire. All the questions in the survey were mandatory to answer to avoid missing data. An informed consent form was attached to the online questionnaire, and each participant consented to participate in the survey after reading the information contained in the consent form. The online survey was developed to be brief, answered within $10 \mathrm{~min}$, and, simultaneously, obtain important information relevant to the objectives of the study. Since participation was voluntary, and the data obtained were anonymous and untraceable, it was assumed that participants responded with honesty and without fear of judgment.

\section{Measurement of associated risk factors of perinatal depression}

The first part of the questionnaire consisted of sociodemographic characteristics and questions for identifying factors increasing the risk of perinatal depression as well whether the women attending antenatal and postnatal clinics were screened for perinatal depression. Sociodemographic questions that were included in this questionnaire included age (classified as less than 24, 25 to 29, 30 to 34 , and 35 and older); marital status (single, married, living together, separated/divorced); education (high school, collage or master certificate); number of children born to the mothers who were still living $(0,1,2,3,4$ or more); and whether the child or pregnancy was planned (yes/no). Five were about family ties, family role and the emotional support the participants received from their family and friends which was scored, i.e., the higher the score, the greater the social support. From question 6 till 11 the participants were asked about 
their partner's role, the nature of their relationship and if there was any verbal, emotional, or physical intimate partner violence. It was assumed that the higher the score, the lesser the partner support. Community's perception of mental health varies across the culture and people's beliefs regarding mental illness are also one of the main factors leading to stigmatization and labelling this might have an enormously negative effect on the mental health of the women in our study hence the increased risk of perinatal depression in women at the perinatal period this was measured through question 12 . The participants were asked if they were screened for depression during their routine obstetric check-ups in antenatal or postnatal care centers in hospitals in Kuwait, and if yes, the participants were asked about the quality of the screening, and their satisfaction with the way the screening was performed. Questions $13,14,15,16$, and 17 were related to COVID-19 pandemic including assessing the difficulties that women faced in regular check-ups, online consultations, and the fears of COVID-19. The questionnaire was initially developed in English and later translated into Arabic.

\section{Assessment of high-risk perinatal depression by using Edinburgh postnatal depression scale}

The second part of the questionnaire was the Edinburgh postnatal depression scale was used to determine the prevalence of high-risk perinatal depression. It is a widely used 10-item self-reported instrument, specifically designed for assessing both prenatal as well as postnatal depression; it has a sensitivity of $86 \%$, specificity of $78 \%$, and a positive predictive value of $73 \%$. The Edinburgh postnatal depression scale consists of 10 short questions with a choice of four answers that closely reflected how the women were feeling over the past 7 days. Scores were recorded as $0,1,2$, and 3 according to symptom severity. Certain question items having 3, 2, 1 and 0 were scored in a reverse manner. The total score was determined by adding together the scores for each of the 10 items ranging from 0-30. Participants who scored 13 or above were considered likely to be suffering from a high risk of depression and should seek medical attention, participants who scored 10-12 were at moderate risk of perinatal depression and those who scored 9 or less were at a low risk of perinatal depression. After receiving permission to use, we used the Arabic version of Edinburgh postnatal depression scale translated by the ministry of health in Bahrain.

\section{Statistical Analysis}

The data were analyzed by using the Statistical Package for Social Sciences (SPSS), version 28. Descriptive statistics (frequencies and percentages) and 95\% confidence intervals were used to estimate the prevalence of antenatal depression and to describe the sample characteristics., whereas the mean and standard deviations were computed for the quantitative variables. The binary outcome variable of perinatal depression among women was calculated by adding the frequency under the categories of "depression possible", "fairly high possibility of depression", and "probable depression" as YES and "depression not likely" as NO. Chisquare test was applied to measure the association for the categorical variables (Perinatal depression and no perinatal depression). Independent sample ttest was used to compare two independent quantitative variables. A p value $<0.05$ was considered statistically significant. 


\section{Results}

\section{Socio-demographic characteristics}

A total of 500 questionnaires were distributed; and after applying the exclusion criteria, a total of 158 respondents were included for the purpose of this study. The age of the respondents ranged between 18 and 39 years, whereas the majority (76) women (48.1\%) were in the age range of 25 to 34 years followed by forty-six respondents (29.1\%) over 35 years and thirty-six women (22.8\%) aged between 18 and 24 years. One hundred and fifty-three (96.8\%) women were married and the remaining five (3.2\%) were either divorced or widowed. Regarding the educational level of the respondents, most of them had attended at least a college or a university, in which 128 women (81\%) had college education and 10 respondents (6.3\%) had university degree, and the remaining 20 women (12.7\%) had high school or lower education level. In addition, regarding their occupation status at the time of the study, most respondents $(70.3 \%)$ were employed, $13.9 \%$ did not work, and $15.8 \%$ were students.

Regarding the obstetric characteristics, 51 (32.3\%) women had one child or no children. From the remaining respondents, forty-two $(26.6 \%)$ and forty $(25.3 \%)$ women had two and four or more children respectively, while twenty-five (15.8\%) had three children. As for the number of pregnancies among the total 158 respondents, a significant majority of them 59 (37.3\%) had been pregnant four or more times, followed by 41 women $(25.9 \%)$ who had two pregnancies, and 35 (22.2\%) women had been pregnant once. In addition, 23 (14.6\%) women had three pregnancies. At the time of the study, 119 (75.3\%) women were in their third trimester of pregnancy and the remaining 39 women $(24.7 \%)$ were in the postpartum stage, more specifically seven days after birth. The data also highlights those 105 (66.5\%) women were unaware of the screening process for perinatal depression both during and after pregnancy and most of them $(149$ or $94.3 \%)$ had not undergone a perinatal screening test (Table 1$)$. We found that perinatal depression was unlikely in $52(32.9 \%)$, possible in 31 (19.6\%) highly possible in $23(14.6 \%)$, and probable in $52(32.9 \%)$ women (Table 2). 
Table 1

Sociodemographic profile of the study participants $(n=158)$

n (\%)

Age in years

$18-24$

$36(22.8)$

$25-34$

$76(48.1)$

$\geq 35$

$46(29.1)$

Level of education

High school or below

$20(12.7)$

College

$128(81)$

Higher studies

$10(6.3)$

\section{Current Occupation}

Working

$111(70.3)$

Not working

$22(13.9)$

Student

25 (15.8)

Marital status

Married

$153(96.8)$

Divorced / Widow

$5(3.2)$

Number of previous pregnancies

One

Two

41 (25.9)

Three

$23(14.6)$

$\geq 4$ times

59 (37.3)

Number of children

$\leq 1$ child

$51(32.3)$

Two children

$42(26.6)$

Three children 25 (15.8)

$\geq 4$ children

$40(25.3)$

Perinatal period 
Third trimester

Postpartum (7 days after birth)

$39(24.7)$

Awareness about screening process for perinatal depression during and after pregnancy

Yes

No

Screened for perinatal depression

Yes

No

Table 2

Prevalence of Perinatal depression among women in Kuwait $(n=158)$

\section{Categories based upon the scoring from the Edinburgh postnatal depression \\ $\mathrm{n}(\%)$ \\ 95\% C.I scale}

Depression unlikely

Depression possible

Fairly high Possibility of depression

Probable depression

\section{2}

(32.9)

31

(19.6)

23

(14.6)

52

(32.9)
24.7-

39.9

13.9-

25.9

9.5-20.9

25.9-

40.5

Table 3 shows the factors associated with the risk of the occurrence of perinatal and postnatal depression and the respondents' perceptions toward them, wherein their responses express agreement, disagreement, or a neutral stance regarding the risk factors. The Likert scale was used to calculate the averages and standard deviations in the statistical data. The Likert scale questions consisted of five categories of strongly Disagree, disagree, neutral, strongly agree and agree, with a value from 1 to 5 . The first two categories were merged into a single category of disagree, and last two into a single category of disagree due to the low data size in each cell. A higher score near 5 means the score favors agreement and vice versa (Tables 3 and 5). The analysis highlights that relationship with family members, their support and the respondents' attitude towards their pregnancy were statistically significant different across women with or without perinatal depression. Accordingly, the most significant indictors were "I can rely on my family members when I am sick or require care" and "My family always stands by me and try to help" scored the highest, $4.47 \pm 0.76$ and $4.42 \pm 0.85$ respectively. In addition, a sizable number of women, 145 out of 158, agreed with the variable "I was happy with this pregnancy" in which the mean score was $4.51 \pm 0.70$. In contrast, the mean score for the factor "Community's perception toward my 
depression affected me" was $2.17 \pm 1.05$ demonstrating that most of the women disagreed that social perception was a factor related to their perinatal depression. Scores for COVID-19 related factors ranged between 2.72 and $3.37 \pm 1.44$ for the factor "I missed some of my perinatal visits during the pandemic because I was afraid of transmitting the disease to my family" and the lowest of \pm 1.04 for factors "I face difficulties to join online consultation for my perinatal depression" and "I didn't get help during my antenatal care and postnatal care visits" (Table 3).

The statistical differences across sociodemographic characteristics and outcome variable of presence or absence of perinatal depression among women showed a significant difference between the variable related to whether the participant had been screened for depression during pregnancy $(P=0.031)$. However, the results were not statistically significantly across sociodemographic variables of age, educational qualification, employment status, marital status, and the occurrence of perinatal depression $(P>0.05)$ (Table 4).

Scores for variables representing support and help were higher among the normal women than with perinatal depression $(P<0.001)$. Similarly, factors related to comfort level of sharing feelings with family and friends and getting help from family when sick or requiring care also had higher scores for normal women $(P<0.01)$. In addition, a caring and supportive husband, a sound marital relationship and having a trusted confidante also had higher mean scores. The result also shows a statistically significant difference (P0.006) when the women were happy with the pregnancy. In contrast, the factor of community perception toward the women's depression were lower in women with perinatal depression (Table 5). 
Table 3

The mean scores for the response of the associated factors on the Likert scale items assessing perinatal depression in women in Kuwait

\begin{tabular}{|c|c|c|c|c|}
\hline & $\begin{array}{l}\text { Disagree* } \\
\text { n (\%) }\end{array}$ & $\begin{array}{l}\text { Neutral } \\
\text { n (\%) }\end{array}$ & $\begin{array}{l}\text { Agree } \\
\mathrm{n}(\%)\end{array}$ & $\begin{array}{l}\text { Mean } \\
\pm \text { SD }\end{array}$ \\
\hline My family always stand by me and try to help & $8(5.1)$ & $\begin{array}{l}10 \\
(6.3)\end{array}$ & $\begin{array}{l}140 \\
(88.6)\end{array}$ & $\begin{array}{l}4.42 \\
\pm \\
0.85\end{array}$ \\
\hline I am comfortable sharing my feelings with my family & $5(3.2)$ & $\begin{array}{l}14 \\
(8.9)\end{array}$ & $\begin{array}{l}139 \\
(88)\end{array}$ & $\begin{array}{l}4.38 \\
\pm \\
0.80\end{array}$ \\
\hline $\begin{array}{l}\text { I Can rely on my family members when I am sick or require } \\
\text { care }\end{array}$ & $6(3.8)$ & $5(3.2)$ & $\begin{array}{l}147 \\
(93)\end{array}$ & $\begin{array}{l}4.47 \\
\pm \\
0.76\end{array}$ \\
\hline $\begin{array}{l}\text { I can easily talk about my problems and thoughts with my } \\
\text { friends }\end{array}$ & $29(18.4)$ & $\begin{array}{l}35 \\
(22.2)\end{array}$ & $\begin{array}{l}94 \\
(59.5)\end{array}$ & $\begin{array}{l}3.64 \\
\pm \\
1.12\end{array}$ \\
\hline I have someone that I can trust and seek help from & $12(7.6)$ & $8(5.1)$ & $\begin{array}{l}138 \\
(87.3)\end{array}$ & $\begin{array}{l}4.33 \\
\pm \\
0.99\end{array}$ \\
\hline My husband is supportive and considerate & $13(8.2)$ & $\begin{array}{l}14 \\
(8.9)\end{array}$ & $\begin{array}{l}131 \\
(82.9)\end{array}$ & $\begin{array}{l}4.21 \\
\pm \\
0.98\end{array}$ \\
\hline I feel safe in my relationship with my husband & $9(5.7)$ & $\begin{array}{l}18 \\
(11.4)\end{array}$ & $\begin{array}{l}131 \\
(82.9)\end{array}$ & $\begin{array}{l}4.29 \\
\pm \\
0.91\end{array}$ \\
\hline I'm worried about sharing my thoughts with my husband & $90(57)$ & $\begin{array}{l}34 \\
(21.5)\end{array}$ & $\begin{array}{l}34 \\
(21.5)\end{array}$ & $\begin{array}{l}2.46 \\
\pm \\
1.20\end{array}$ \\
\hline $\begin{array}{l}\text { There were situations in my relationship where I have felt } \\
\text { afraid and unsafe }\end{array}$ & $87(55.1)$ & $\begin{array}{l}28 \\
(17.7)\end{array}$ & $\begin{array}{l}43 \\
(27.2)\end{array}$ & $\begin{array}{l}2.59 \\
\pm \\
1.27\end{array}$ \\
\hline $\begin{array}{l}\text { I have been emotionally or physically or verbally abused by } \\
\text { my partner }\end{array}$ & $\begin{array}{l}111 \\
(70.3)\end{array}$ & $\begin{array}{l}13 \\
(8.2)\end{array}$ & $\begin{array}{l}34 \\
(21.5)\end{array}$ & $\begin{array}{l}2.18 \\
\pm \\
1.25\end{array}$ \\
\hline I was happy with this pregnancy & $3(1.9)$ & $\begin{array}{l}10 \\
(6.3)\end{array}$ & $\begin{array}{l}145 \\
(91.8)\end{array}$ & $\begin{array}{l}4.51 \\
\pm \\
0.70\end{array}$ \\
\hline $\begin{array}{l}\text { The community's perception toward my depression } \\
\text { affected me }\end{array}$ & $\begin{array}{l}105 \\
(66.5)\end{array}$ & $\begin{array}{l}37 \\
(23.4)\end{array}$ & $\begin{array}{l}16 \\
(10.1)\end{array}$ & $\begin{array}{l}2.17 \\
\pm \\
1.05\end{array}$ \\
\hline $\begin{array}{l}\text { During the COVID- } 19 \text { pandemic, I faced difficulties to join } \\
\text { online consultation for my perinatal depression }\end{array}$ & $12(19)$ & $\begin{array}{l}22 \\
(34.9)\end{array}$ & $\begin{array}{l}29 \\
(46)\end{array}$ & $\begin{array}{l}3.30 \\
\pm \\
0.98\end{array}$ \\
\hline
\end{tabular}




\begin{tabular}{|c|c|c|c|c|}
\hline & $\begin{array}{l}\text { Disagree* } \\
\mathrm{n}(\%)\end{array}$ & $\begin{array}{l}\text { Neutral } \\
\mathrm{n}(\%)\end{array}$ & $\begin{array}{l}\text { Agree } \\
\mathrm{n}(\%)\end{array}$ & $\begin{array}{l}\text { Mean } \\
\pm S D\end{array}$ \\
\hline $\begin{array}{l}\text { During the COVID-19 pandemic, it was difficult to find } \\
\text { online consultation for perinatal depression }\end{array}$ & $12(19)$ & $\begin{array}{l}21 \\
(33.3)\end{array}$ & $\begin{array}{l}30 \\
(47.6)\end{array}$ & $\begin{array}{l}3.37 \\
\pm \\
1.04\end{array}$ \\
\hline $\begin{array}{l}\text { During the COVID-19 pandemic, I didn't get the help I need } \\
\text { for my depressive symptoms from the online consultation }\end{array}$ & $17(27)$ & $\begin{array}{l}23 \\
(36.5)\end{array}$ & $\begin{array}{l}23 \\
(36.5)\end{array}$ & $\begin{array}{l}3.17 \\
\pm \\
0.98\end{array}$ \\
\hline $\begin{array}{l}\text { I was afraid of transmitting the disease to my family during } \\
\text { my antenatal care and postnatal care visits during the } \\
\text { COVID-19 pandemic }\end{array}$ & $41(25.9)$ & $\begin{array}{l}37 \\
(23.4)\end{array}$ & $\begin{array}{l}80 \\
(50.6)\end{array}$ & $\begin{array}{l}3.25 \\
\pm \\
1.35\end{array}$ \\
\hline $\begin{array}{l}\text { I missed some of my perinatal visits during the pandemic } \\
\text { because I was afraid of transmitting the } \\
\text { disease to my family }\end{array}$ & $83(52.5)$ & $\begin{array}{l}20 \\
(12.7)\end{array}$ & $\begin{array}{l}55 \\
(34.8)\end{array}$ & $\begin{array}{l}2.72 \\
\pm \\
1.44\end{array}$ \\
\hline
\end{tabular}


Table 4

Cross-tabulation of sociodemographic variables with perinatal depression

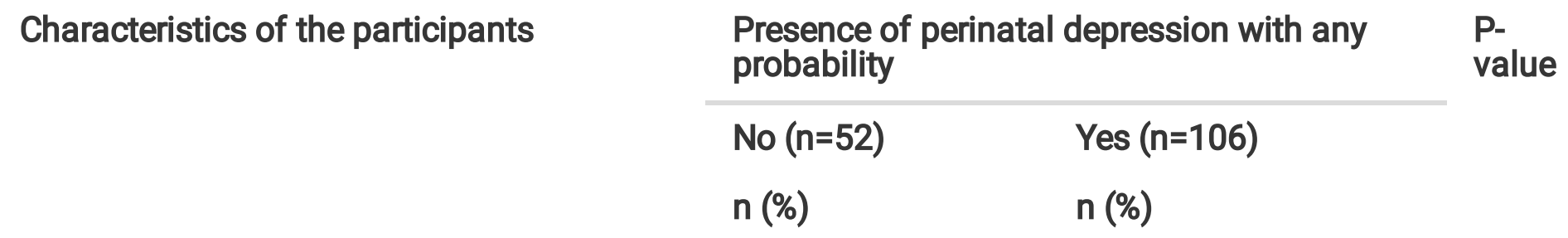

Age in years

$\begin{array}{llll}18-24 & 8(22.2) & 28(77.8) & 0.295 \\ 25-34 & 27(35.5) & 49(64.5) & \\ \geq 35 & 17(37) & 29(63)\end{array}$

\section{Education level}

High school or below

$6(30)$

$14(70)$

College

$42(32.8)$

$86(67.2)$

Higher studies

$4(40)$

$6(60)$

\section{Current Occupation}

Working

$38(34.2)$

$73(65.8)$

Not working

10 (45.5)

12 (54.5)

Student

4 (16)

21 (84)

Marital status

Married

50 (32.7)

103 (67.3)

0.664

Divorced/Widow

$2(40)$

$3(60)$

Number of pregnancies

One time

$9(25.7)$

26 (74.3)

0.782

Two times

$14(34.1)$

27 (65.9)

Three times

8 (34.8)

15 (65.2)

$\geq 4$ times

21 (35.6)

38 (64.4)

Number of children

$\leq 1$ child

$13(25.5)$

38 (74.5)

0.108

Two children

15 (35.7)

27 (64.3)

Three children

$13(52)$

12 (48) 


\begin{tabular}{|c|c|c|c|}
\hline \multirow[t]{3}{*}{ Characteristics of the participants } & \multicolumn{2}{|c|}{$\begin{array}{l}\text { Presence of perinatal depression with any } \\
\text { probability }\end{array}$} & \multirow[t]{3}{*}{$\begin{array}{l}\mathrm{P}- \\
\text { value }\end{array}$} \\
\hline & No $(n=52)$ & Yes $(n=106)$ & \\
\hline & $\mathrm{n}(\%)$ & n (\%) & \\
\hline$\geq 4$ children & $11(27.5)$ & $29(72.5)$ & \\
\hline \multicolumn{4}{|l|}{ Perinatal period } \\
\hline Third trimester & $42(35.3)$ & $77(64.7)$ & \multirow[t]{2}{*}{0.266} \\
\hline Postpartum (7 days after birth) & $10(25.6)$ & $29(74.4)$ & \\
\hline \multicolumn{4}{|l|}{$\begin{array}{l}\text { Awareness about screening during } \\
\text { perinatal period }\end{array}$} \\
\hline Yes & $13(24.5)$ & $40(75.5)$ & \multirow[t]{2}{*}{0.111} \\
\hline No & $39(37.1)$ & $66(62.9)$ & \\
\hline \multicolumn{4}{|l|}{ Screened for perinatal depression } \\
\hline Yes & $0(0)$ & $9(100)$ & \multirow[t]{2}{*}{0.031} \\
\hline No & $52(34.9)$ & 97 (65.1) & \\
\hline
\end{tabular}


Comparison of the response of pregnant women with levels of perinatal depression

Perinatal depression

\begin{tabular}{|c|c|c|c|}
\hline & $\begin{array}{l}\text { No } \\
\text { (Mean } \\
\pm \text { SD) }\end{array}$ & $\begin{array}{l}\text { Yes } \\
\text { (Mean } \\
\pm \text { SD) }\end{array}$ & $\begin{array}{l}\mathrm{P}- \\
\text { value }\end{array}$ \\
\hline My family always stand by me and try to help & $\begin{array}{l}4.77 \pm \\
0.51\end{array}$ & $\begin{array}{l}4.25 \pm \\
0.93\end{array}$ & $<0.001$ \\
\hline I am comfortable sharing my feelings with my family & $\begin{array}{l}4.65 \pm \\
0.62\end{array}$ & $\begin{array}{l}4.25 \pm \\
0.85\end{array}$ & $<0.01$ \\
\hline I Can rely on my family members when I am sick or require care & $\begin{array}{l}4.73 \pm \\
0.49\end{array}$ & $\begin{array}{l}4.34 \pm \\
0.84\end{array}$ & $<0.01$ \\
\hline I can easily talk about my problems and thoughts with my friends & $\begin{array}{l}4.06 \pm \\
1.02\end{array}$ & $\begin{array}{l}3.43 \pm \\
1.11\end{array}$ & $<0.01$ \\
\hline I have someone that I can trust and seek help from & $\begin{array}{l}4.52 \pm \\
0.94\end{array}$ & $\begin{array}{l}4.24 \pm \\
1.00\end{array}$ & $<0.05$ \\
\hline My husband is supportive and considerate & $\begin{array}{l}4.50 \pm \\
0.75\end{array}$ & $\begin{array}{l}4.07 \pm \\
1.04\end{array}$ & $<0.05$ \\
\hline I feel safe in my relationship with my husband & $\begin{array}{l}4.46 \pm \\
0.83\end{array}$ & $\begin{array}{l}4.21 \pm \\
0.93\end{array}$ & 0.068 \\
\hline I'm worried about sharing my thoughts with my husband & $\begin{array}{l}2.40 \pm \\
1.29\end{array}$ & $\begin{array}{l}2.48 \pm \\
1.16\end{array}$ & 0.519 \\
\hline $\begin{array}{l}\text { There were situations in my relationship where I have felt afraid and } \\
\text { unsafe }\end{array}$ & $\begin{array}{l}2.35 \pm \\
1.19\end{array}$ & $\begin{array}{l}2.72 \pm \\
1.30\end{array}$ & 0.087 \\
\hline I have been emotionally or physically or verbally abused by my partner & $\begin{array}{l}1.92 \pm \\
1.06\end{array}$ & $\begin{array}{l}2.30 \pm \\
1.32\end{array}$ & 0.119 \\
\hline I was happy with this pregnancy & $\begin{array}{l}4.73 \pm \\
0.49\end{array}$ & $\begin{array}{l}4.40 \pm \\
0.76\end{array}$ & $<0.05$ \\
\hline The community's perception toward my depression affected me & $\begin{array}{l}1.71 \pm \\
0.89\end{array}$ & $\begin{array}{l}2.40 \pm \\
1.06\end{array}$ & $<0.001$ \\
\hline $\begin{array}{l}\text { During the COVID-19 pandemic, I faced difficulties to join online } \\
\text { consultation for my perinatal depression }\end{array}$ & $\begin{array}{l}3.00 \pm \\
1.00\end{array}$ & $\begin{array}{l}3.37 \pm \\
0.97\end{array}$ & 0.302 \\
\hline $\begin{array}{l}\text { During the COVID- } 19 \text { pandemic, it was difficult to find online } \\
\text { consultation for perinatal depression }\end{array}$ & $\begin{array}{l}3.09 \pm \\
0.94\end{array}$ & $\begin{array}{l}3.42 \pm \\
1.05\end{array}$ & 0.222 \\
\hline $\begin{array}{l}\text { During the COVID-19 pandemic, I didn't get the help I need for my } \\
\text { depressive symptoms from the online consultation }\end{array}$ & $\begin{array}{l}2.91 \pm \\
0.70\end{array}$ & $\begin{array}{l}3.23 \pm \\
1.02\end{array}$ & 0.330 \\
\hline $\begin{array}{l}\text { I was afraid of transmitting the disease to my family during my } \\
\text { antenatal care and postnatal care visits during the COVID-19 pandemic }\end{array}$ & $\begin{array}{l}2.98 \pm \\
1.41\end{array}$ & $\begin{array}{l}3.38 \pm \\
1.31\end{array}$ & 0.084 \\
\hline
\end{tabular}




\section{Perinatal \\ depression}

I missed some of my perinatal visits during the pandemic because I

was afraid of transmitting the disease to my family

$2.33 \pm$

1.31

$2.92 \pm<0.05$

1.46

\section{Discussion}

Majority of the women in our study had perinatal depression of varying probability. Studies of the prevalence of perinatal depression among pregnant women emphasize that this condition is a global phenomenon, where approximately $11.9 \%$ of pregnant women worldwide experience major or minor depressive episodes during their pregnancy $(1,2,6)$. Other regional studies have reported significantly higher perinatal depression rates such as $25-50 \%$ in Oman and Saudi Arabia (7) and $46 \%$ in Kuwait (24). The difference in prevalence of perinatal depression between this study and the other studies is possibly because out of the 158 pregnant women sampled, only 9 of them had been screened for perinatal depression during their regular pregnancy checkup visits.

The findings of this study demonstrated that sociodemographic characteristics related to the women's age, educational level, marital and employment statuses were not significant determinants of perinatal depression although other studies have reported that sociodemographic, economic differences and marital status can significantly affect the prevalence of perinatal depression $(5,25)$. A possible explanation for the deviating results in this study to those found in other comparable studies could be that a significant majority of the sampled participants were married, had college or higher educational qualifications, and were employed, and therefore did not have the demographic characteristics of the samples included in other studies. However, the association between inadequate family and social support and prenatal depression has been well-documented (5). Experiencing lack of baby's father's trust and support was found to be a statistically significant factor of perinatal depression during pregnancy. This is possibly because women who receive their spouse's assistance and care during pregnancy feel empowered and confident to deal with their pregnancy. Not having family's and friends' help and support during pregnancy were also observed to be statistically significant factors associated with perinatal depression in our study. This is possibly because during pregnancy women feel more vulnerable and insecure due to physical, psychological, and hormonal changes, and need the care and support of their family members (25). These findings were also consistent with the outcomes of other studies conducted elsewhere $(5,13,25)$. It is also possible that depressed women might feel that the care and support they receive is insufficient. Studies have consistently shown maternal anxiety and concern about pregnancy as strong predictors of perinatal depression (26-28). Although a significant majority of the women in this study agreed that they were happy with their pregnancy, $20 \%$ of these women had a high probability of perinatal depression. It is possible that these women were unwilling to reveal their feelings due to concerns about mental health treatment methods or lack of awareness of perinatal depression. Another reason could be their perceptions of social or self-stigma toward depression. Such concerns were also raised in other similar studies on perinatal depression $(5,17)$ 
Several studies report that perinatal depression is underdiagnosed and not recognized as pregnant women are not routinely screened for their mental wellbeing, not also by general practitioners $(13,17,29)$. Avalos et al. emphasized the need for perinatal screening using a validated tool to increase the rate of detecting depression (17). In 2015, the American College of Obstetricians and Gynecologists recommended that obstetricians screen women for symptoms of depression at least once during the perinatal period (3). The findings of this study indicated that approximately $95 \%$ of the women had not been screened for perinatal depression even once during their follow- up checkups. In addition, 6 out of every 10 women mentioned that they were not aware of the need for screening tests for depression during pregnancy.

The findings of this study about the impact of COVID -19 pandemic on perinatal and postnatal depression were also significant. It was found that lack of access to direct consultations with physicians as well as difficulty to find or join online consultations were clearly exacerbating factors of perinatal depression. In addition, the fear of contracting COVID -19 and transmitting the virus to family members was found to be important. These outcomes are comparable to the findings in studies conducted during the COVID-19 pandemic in China $(22,23)$. COVID -19 pandemic compounded the perinatal depression problem to the extent that many women who experienced perinatal depression were unable to seek the assistance they needed, particularly during the lockdown period when many online obstetric consultations were no longer readily available (23). It is quite possible that the pandemic was most severe for some women and that the prevalence of severe perinatal depression may have increased, as women were more likely to experience anxiety, uncertainty, and general fear that often leads to depression. Also, because many women in our study were worried that they would contract the Severe Acute Respiratory Syndrome Coronavirus 2, affecting them and their babies, it might have kept them home, as they adopted preventative measures. As such, women may have refrained from seeking antenatal care that they needed, which may have led to greater mental health issues.

It is crucial that the women should continue additional screening during their antenatal and postpartum care visits. Further, the American College of Obstetricians and Gynecologists recommends several validated assessment tools that could be used for screening perinatal depression. For women to accept their illness and share their depressive episodes, they must also have a certain level of trust and rapport with their physicians. Pregnancy and motherhood are considered as joyful experiences by society, so women may feel uncomfortable sharing their depressive feelings. Because the level of trust and comfort that a pregnant woman feels towards her physician is deep, gynecologists or obstetricians play a vital role in the screening procedure. If obstetric care providers are informed about the clinical implications of risk factors for depression, they can more efficiently identify pregnant women who are potentially prone to depression. For instance, normal pregnancy shares some signs and symptoms of depression like experiencing emotional changes, insomnia, and weight gain.

\section{Strengths and Limitations}


This study has several strengths. Firstly, it was cost-effective for the researchers because a cross sectional survey-based design was used to gather data from the population sample. In addition, this study was conducted during the COVID-19 pandemic, which allowed the researchers to gain a different perspective on factors associated with perinatal depression, and the findings can contribute to other studies on perinatal depression in Kuwait and in other similar settings. Finally, from a broader perspective, the study reiterates the importance of integrating mental health screening services with maternal health visits. This can also help in planning treatment methods and preventive interventions to reduce perinatal depression and mental health problems.

However, this study also has some limitations. First, it was completed during the COVID-19 pandemic and hence, it was difficult for the researchers to access the antenatal and postnatal clinics in Kuwait where the participants were attending. The estimated prevalence of perinatal depression was lower in our study compared to the earlier estimates in the region; a larger sample may elicit a higher prevalence. In addition, the data required for the study were also inaccessible due to the pandemic lockdown. Furthermore, as this was an online survey-based study, the accuracy of the responses from the participants could be limited, which might affect the validity of the findings. A final limitation was the size of the population sample. Although 500 survey questionnaires were distributed, based on the exclusion criteria only 158 participants finally responded. Due to the small sample size, it is possible that the statistical results would not identify significant relationships which could then be generalized for a larger population. It is also possible that more women with perinatal depression didn't want to respond to the online questionnaire. Studies with better designs evaluating the women's burden of perinatal depression and their satisfaction with the screening and subsequent treatment are recommended.

\section{Conclusion}

Majority of the women in our study had a probability of perinatal depression of varying degree. Given the high probability of the prevalence of perinatal depression, and a lack of screening for most women in this study, this is significant in that it strongly urges the need to integrate screening for depression around pregnancy in Kuwait. At the national healthcare level, implementation of routine screening for depression using a validated screening tool is strongly recommended. Experiencing a lack of father's care and support, lack of familial and social care and support, maternal anxiety related to pregnancy and community's perception towards depression were factors associated with perinatal depression. Family and husband's support and involvement in the pregnancy care and creating better awareness of the prevalence of perinatal depression to reduce social and self-stigma are recommended to reduce the risk of depression among pregnant women.

\section{Declarations}

\section{Ethics approval and consent to participate}


The study was carried out in accordance with the guidelines of Declaration of Helsinki. Ethical approval was obtained from the Research and Ethics Committee at the College of Medicine and Medical Sciences of Arabian Gulf University (E45-PI-4/20). To ensure privacy and confidentiality the contact details and the name of the respondents and will not be taken instead of names each questionnaire had a unique identification number. All participants were informed about the aim of the study and assured that the information would only be used for research purposes at the beginning of the online questionnaire. Informed consent will be provided by each participant prior to their voluntary participation by ticking the "Yes, I agree and hereby give my informed consent" box, and not provided by ticking "No thanks, I do not give my consent" box on the online form. By ticking the no box participant will be excluded from the study as they refuse to give an informed consent.

\section{Consent for publication}

All participants consented to their data being published as part of this study's analysis.

\section{Availability of data and materials}

The datasets used and/or analyzed during the current study are available upon reasonable request from the senior author (Dr. Jamil Ahmed) at: jamilmga@agu.edu.bh

\section{Competing interests}

The authors declare that there are no conflicts of interest.

\section{Funding}

No funding was received for this research.

\section{Authors' contributions}

Conceptualization: RA, MA, AMA, DA, LA, DN, ATA, SM, LJA and JA. Study Design: RA, MA, AMA, DA, LA, DN, ATA, SM, LJA, and JA. Data Collection: RA, MA, AMA, DA, LA, DN, AA, SM, and LJA. Data Analysis RA, MA, AMA, DA, LA, DN, ATA, SM, LJA, and AJA. Data Interpretation: RA, MA, AMA, DA, LA, DN, ATA, SM, and LJA. Writing - original draft: RA, MA, AMA, DA, LA, DN, ATA, SM, LJA. Writing - review and editing: AJA, JA. Supervision: JA. All authors consented to the publication of this manuscript. All named authors read and approved the final manuscript.

\section{Acknowledgements}

NA

\section{Authors' information}

Akk authors are affiliated with the department of Family and Community Medicine Dept. College of Medicine and Medical Sciences, Arabian Gulf University, Salmaniya Medical Complex, P.O Box 26671, 


\section{References}

1. Alhusen JL, Alvarez C. Perinatal depression: A clinical update. Nurse Pract. 2016;41(5):50-5.

2. World Health Organization. Maternal and perinatal health 2021 [Available from: https://www.who.int/reproductivehealth/publications/maternal_perinatal_health/en/.

3. American College of Obstetricians and Gynecologists. ACOG Committee Opinion No. 757: Screening for Perinatal Depression. Obstet Gynecol. 2018;132(5):e208-e12.

4. Faisal-Cury A, Levy RB, Azeredo CM, Matijasevich A. Prevalence and associated risk factors of prenatal depression underdiagnosis: A population-based study. Int J Gynaecol Obstet. 2021;153(3):469-75.

5. Sheeba B, Nath A, Metgud CS, Krishna M, Venkatesh S, Vindhya J, et al. Prenatal Depression and Its Associated Risk Factors Among Pregnant Women in Bangalore: A Hospital Based Prevalence Study. Front Public Health. 2019;7:108.

6. Pellowski JA, Bengtson AM, Barnett W, DiClemente K, Koen N, Zar HJ, et al. Perinatal depression among mothers in a South African birth cohort study: Trajectories from pregnancy to 18 months postpartum. J Affect Disord. 2019;259:279-87.

7. Naja S, Al-Kubaisi N, Chehab M, Al-Dahshan A, Abuhashem N, Bougmiza I. Psychometric properties of the Arabic version of EPDS and BDI-II as a screening tool for antenatal depression: evidence from Qatar. BMJ Open. 2019;9(9):e030365.

8. Gerbasi ME, Kosinski M, Meltzer-Brody S, Acaster S, Fridman M, Huang MY, et al. Achieving clinical response in postpartum depression leads to improvement in health-related quality of life. Curr Med Res Opin. 2021;37(7):1221-31.

9. de Los Reyes S, Dude A, Adams M, Castille D, Ouyang DW, Plunkett BA. The Association between Maternal Body Mass Index and the Risk of Perinatal Depression. Am J Perinatol. 2021.

10. Taylor BL, Howard LM, Jackson K, Johnson S, Mantovani N, Nath S, et al. Mums Alone: Exploring the Role of Isolation and Loneliness in the Narratives of Women Diagnosed with Perinatal Depression. J Clin Med. 2021;10(11).

11. van Lee L, Chia A, Phua D, Colega M, Padmapriya N, Bernard JY, et al. Multiple modifiable lifestyle factors and the risk of perinatal depression during pregnancy: Findings from the GUSTO cohort. Compr Psychiatry. 2020;103:152210.

12. Garman EC, Schneider M, Lund C. Perinatal depressive symptoms among low-income South African women at risk of depression: trajectories and predictors. BMC Pregnancy Childbirth. 2019;19(1):202.

13. Yedid Sion M, Harlev A, Weintraub AY, Sergienko R, Sheiner E. Is antenatal depression associated with adverse obstetric and perinatal outcomes? J Matern Fetal Neonatal Med. 2016;29(6):863-7.

14. Greene MM, Rossman B, Patra K, Kratovil AL, Janes JE, Meier PP. Depression, anxiety, and perinatalspecific posttraumatic distress in mothers of very low birth weight infants in the neonatal intensive 
care unit. J Dev Behav Pediatr. 2015;36(5):362-70.

15. Dadi AF, Miller ER, Woodman RJ, Azale T, Mwanri L. Effect of perinatal depression on risk of adverse infant health outcomes in mother-infant dyads in Gondar town: a causal analysis. BMC Pregnancy Childbirth. 2021;21(1):255.

16. Ban L, Gibson JE, West J, Tata LJ. Association between perinatal depression in mothers and the risk of childhood infections in offspring: a population-based cohort study. BMC Public Health. 2010;10:799.

17. Avalos LA, Raine-Bennett T, Chen H, Adams AS, Flanagan T. Improved Perinatal Depression Screening, Treatment, and Outcomes With a Universal Obstetric Program. Obstet Gynecol. 2016;127(5):917-25.

18. Lara-Cinisomo S, Clark CT, Wood J. Increasing Diagnosis and Treatment of Perinatal Depression in Latinas and African American Women: Addressing Stigma Is Not Enough. Womens Health Issues. 2018;28(3):201-4.

19. Long MM, Cramer RJ, Bennington L, Morgan FG, Wilkes CA, Fontanares AJ, et al. Perinatal depression screening rates, correlates, and treatment recommendations in an obstetric population. Fam Syst Health. 2020;38(4):369-79.

20. Boyce PM, Judd F. Screening for perinatal depression: is it enough? Med J Aust. 2019;210(1):19-20.

21. Terrazas C, Segre LS, Wolfe C. Moving beyond depression screening: integrating perinatal depression treatment into OB/GYN practices. Prim Health Care Res Dev. 2018;20:e52.

22. Ellington K. Perinatal depression screening: Improving outcomes during COVID-19. Nursing. 2021;51(10):50-4.

23. Sun G, Wang Q, Lin Y, Li R, Yang L, Liu X, et al. Perinatal Depression of Exposed Maternal Women in the COVID-19 Pandemic in Wuhan, China. Front Psychiatry. 2020;11:551812.

24. Alhamadan N, Ajan A, Alali A, Badr HE. Postpartum depression and health related quality of life: a necessary assessment Int J Fam Commun Med. 2017;1:11-7.

25. Hamel C, Lang E, Morissette K, Beck A, Stevens A, Skidmore B, et al. Screening for depression in women during pregnancy or the first year postpartum and in the general adult population: a protocol for two systematic reviews to update a guideline of the Canadian Task Force on Preventive Health Care. Syst Rev. 2019;8(1):27.

26. Eichler J, Schmidt R, Hiemisch A, Kiess W, Hilbert A. Gestational weight gain, physical activity, sleep problems, substance use, and food intake as proximal risk factors of stress and depressive symptoms during pregnancy. BMC Pregnancy Childbirth. 2019;19(1):175.

27. Lilliecreutz C, Josefsson A, Mohammed H, Josefsson A, Sydsjo G. Mental disorders and risk factors among pregnant women with depressive symptoms in Sweden-A case-control study. Acta Obstet Gynecol Scand. 2021;100(6):1068-74.

28. Yu M, Li H, Xu DR, Wu Y, Liu H, Gong W. Trajectories of perinatal depressive symptoms from early pregnancy to six weeks postpartum and their risk factors-a longitudinal study. J Affect Disord. 2020;275:149-56. 
29. Ford E, Shakespeare J, Elias F, Ayers S. Recognition and management of perinatal depression and anxiety by general practitioners: a systematic review. Fam Pract. 2017;34(1):11-9. 